\title{
Global Lung Function Initiative Equations: The Legacy Starts
}

\author{
Joan B. Soriano ${ }^{a}$ Francisco García-Rio ${ }^{\text {b, c }}$ \\ anstituto de Investigación Hospital Universitario de la Princesa (IISP), Universidad Autónoma de Madrid, \\ bServicio de Neumología, Hospital Universitario La Paz, Universidad Autónoma de Madrid, IdiPAZ, and ${ }^{\mathrm{C} C I B E R}$ de \\ Enfermedades Respiratorias (CIBERES), Madrid, Spain
}

Lung function is a better predictor of total short- and long-term mortality in the general population than other commonly used prognostic risk factors, such as cholesterol, high blood pressure, glycaemia, and others. Indeed, in 1846, Hutchinson [1] coined the term vital capacity (VC), i.e. the capacity for life, because he realized that compromise of this crucial measurement was predictive of premature mortality. Some 40 years ago, Framingham cardiologists and researchers recovered this term when they showed that this lung function measurement was a powerful prognostic indicator of cardiovascular and noncardiovascular mortality $[2,3]$.

In the latest issue of Respiration, Pedone et al. [4] reported new findings from the prolific and well-documented Respiratory Health in the Elderly (Salute Respiratoria nell'Anziano; SARA) cohort of participants, aiming to evaluate the agreement and usefulness of a number of lung function equations for the prediction of $\mathrm{FEV}_{1}$, namely the Global Lung Function Initiative (GLI) [5], the old European Respiratory Society (ERS) [6], and the third National Health and Nutrition Examination Survey (NHANES) [7] as well as their own equation [8], in a chronic obstructive pulmonary disease (COPD) sample of people 70 years of age and older. They also aimed to evaluate the discriminative capacity of \%predicted $\mathrm{FEV}_{1}$

\section{KARGER}

(c) 2016 S. Karger AG, Basel

0025-7931/16/0923-0131\$39.50/0

E-Mail karger@karger.com

www.karger.com/res calculated using these four equations with respect to 5 -year mortality.

We must bear in mind that the NHANES equations are considered valid for patients up to 80 years of age only, while the GLI equation includes patients up to 95 years; however, recently, Luoto et al. [9] expanded it to patients up to 100 years of age, already anticipating subsequent avenues for research [10].

In the study by Pedone et al. [4], agreement was evaluated by the Bland-Altman method, a visual method of data plotting used in analysing the agreement between two different assays (reference equations), where the same parameter (\%predicted $\mathrm{FEV}_{1}$ ) should have a good correlation when $\mathrm{FEV}_{1}$ varies considerably; in contrast, discriminative capacity was assessed by means of mortality rate ratios calculated across quartiles of each measure.

Pedone et al. [4] explored these outcomes in their cohort of 264 elderly COPD patients with a mean age of 75.8 years, mostly men (73\%) with a significant smoking history (35.5 pack-years) and, accordingly, a poor lung function (mean post-bronchodilator $\mathrm{FEV}_{1} 1.5$ ), but with a rather high Barthel index of 92.8, indicating good physical independence in this COPD cohort combined with a high level of activities of daily living. All in all, the really good news was the remarkable overlap between the local

Dr. Joan B. Soriano

Instituto de Investigación Hospital Universitario de la Princesa (IISP)

Universidad Autónoma de Madrid, Diego de León 62

ES-28030 Madrid (Spain)

E-Mail jbsoriano2@gmail.com 
SARA and GLI equations $[8,5]$, showing an excellent agreement overall, with an almost perfect ratio of 1.005 and $95 \%$ confidence intervals of $0.928-1.088$, and reporting a slight underestimation in women and a slight overestimation in men. The agreement of SARA was both lower with the NHANES and old ERS equations. In our view, from this important finding at least three messages may be derived. Again, it has been demonstrated that the old ERS reference equations are particularly inaccurate in women so that their routine use should be discouraged nowadays. The need to use reference equations that include the same age range of individuals to be tested is underlined $[11,12]$. In this sense, the broader availability of specific reference equations for European elderly subjects can be useful $[13,14]$. Finally, the excellent agreement between the local SARA and the GLI equations demonstrates the applicability of this new set of GLI equations which provide a universal solution to the problem of adaptation to age ranges and ethnic groups.

Two limitations are listed in the Discussion section by Pedone et al. [4], namely the use of FVC, not VC, and the larger proportion of male participants. Both issues are common, and even universal, in most previous population spirometry studies. However, other limitations could be considered. As in any observational study with a long follow-up (20 years in the case of the SARA study), there are some inherent limitations worth noting. The original SARA study started in January 1996 with 1,970 participants, and subsequently, there have been dropouts and patients lost to follow-up, so that the study population was eventually reduced to 737 individuals older than 70 years with post-bronchodilator spirometry and with valid vital status, of whom only 264 were included in the analysis as they had objective airflow limitation; likely, a survivor bias is present and still uncontrolled. Other STROBE requirements are to be considered [15]. Another limitation is the absence of a BODE assessment, as all constitu- ent variables were available but not reported. In contrast, the authors reported results according to the GOLD 2011 staging. Finally, it would also be interesting to compare the prognostic value of the different reference equations using the GOLD classification of airflow limitation severity rather than the distribution by $\mathrm{FEV}_{1}$ quartiles. In turn, to complete the prognostic assessment of GLI equations, it seems recommendable to assess their discriminative capacity according to the recent classification of airflow limitation based on the z-score [16].

As reported in the Discussion section, and beyond physiology, the choice of reference equations is of fundamental clinical importance to assess the stage of severity of individual patients and to later tailor their treatment. We must bear in mind that the confirmation of airflow limitation is the first step to diagnose and manage COPD, but we treat patients with symptoms and not only spirometric abnormalities.

However, the very low overall capacity of predicting mortality regardless of the reference equation used is not very surprising with a $C$ statistic lower than 0.44 for all equations. To date, all COPD multicomponent indices but one, the B-AE-D index [17], include spirometry. However, considering that once COPD is clinically diagnosed many patients remain in the same lung function group for years, even with improvements, the role of serially testing spirometry and its single use as a prognosticator is being questioned [18]. This limitation is likely enhanced in elderly COPD patients.

Overall, the work by Pedone et al. [4] confirms that more population spirometry is needed, particularly in the elderly, to update the existing estimates for the benefit of individual patients and public health. Besides, it also reinforces the GLI as a major driver of new respiratory research [19], which has already started a legacy that is expected to be long-lasting [20].

\section{References}

1 Hutchinson J: On the capacity of the lungs, and on the respiratory functions, with a view of establishing a precise and easy method of detecting disease by the spirometer. Med Chir Trans 1846;29:137-252.

$\checkmark 2$ Kannel WB, Lew EA, Hubert HB, Castelli WP: The value of measuring vital capacity for prognostic purposes. Trans Assoc Life Insur Med Dir Am 1980;64:66-83.

-3 Kannel WB, Hubert H, Lew EA: Vital capacity as a predictor of cardiovascular disease: the Framingham study. Am Heart J 1983;105: 311-315.
4 Pedone C, Di Marco Berardino A, Pistelli R, Forastiere F, Bellia V, Antonelli Incalzi R: Can the new global lung initiative equations better stratify the risk of death in elderly people with chronic obstructive pulmonary disease? Respiration 2016;92:16-24.

5 Quanjer PH, Stanojevic S, Cole TJ, Baur X, Hall GL, Culver BH, Enright PL, Hankinson JL, Ip MSM, Zheng J, Stocks J; ERS Global Lung Function Initiative: Multi-ethnic reference values for spirometry for the 3-95-years age range: the global lung function 2012 equations. Eur Respir J 2012;40:1324-1343. 
6 Quanjer PH, Tammeling GJ, Cotes JE, Pedersen OF, Peslin R, Yernault JC: Lung volumes and forced ventilatory flows. Eur Respir J 1993;6(suppl 16):5-40.

7 Hankinson JL, Odencrantz JR, Fedan KB: Spirometric reference values from a sample of the general US population. Am J Respir Crit Care Med 1999;159:179-187.

-8 Pistelli R, Bellia V, Catalano F, Antonelli Incalzi R, Scichilone N, Rengo F; SARA Study Group: Spirometry reference values for women and men aged 65-85 living in southern Europe: the effect of health outcomes. Respiration 2003;70:484-489.

9 Luoto JA, Elmståhl S, Wollmer P, Pihlsgård M: Incidence of airflow limitation in subjects 65-100 years of age. Eur Respir J 2016;47: 461-472.

10 Soriano JB, Suissa S: Ageing lungs and very elderly COPD: anytime and anywhere. Eur Respir J 2016;47:379-381.

11 Miller MR, Hankinson J, Brusasco V, Burgos F, Casaburi R, Coates A, Crapo R, Enright P, van der Grinten CP, Gustafsson P, Jensen R, Johnson DC, MacIntyre N, McKay R, Navajas D, Pedersen OF, Pellegrino R, Viegi G, Wanger J; ATS/ERS Task Force: Standardisation of spirometry. Eur Respir J 2005;26:319-338.
12 Miller MR, Crapo R, Hankinson J, Brusasco V, Burgos F, Casaburi R, Coates A, Enright P, van der Grinten CP, Gustafsson P, Jensen R, Johnson DC, MacIntyre N, McKay R, Navajas D, Pedersen OF, Pellegrino R, Viegi G, Wanger J; ATS/ERS Task Force: General considerations for lung function testing. Eur Respir J 2005;26:153-161.

13 García-Río F, Pino JM, Dorgham A, Alonso A, Villamor J: Spirometric reference equations for European females and males aged 65-85 years. Eur Respir J 2004;24:397-405.

14 Garcia-Rio F, Dorgham A, Pino JM, Villasante C, Garcia-Quero C, Alvarez-Sala R: Lung volume reference values for women and men 65 to 85 years of age. Am J Respir Crit Care Med 2009; 180:1083-1091.

15 von Elm E, Altman DG, Egger M, Pocock SJ, Gøtzsche PC, Vandenbroucke JP; STROBE Initiative: The Strengthening the Reporting of Observational Studies in Epidemiology (STROBE) statement: guidelines for reporting observational studies. Ann Intern Med 2007; 147:573-577.

16 Quanjer PH, Pretto JJ, Brazzale DJ, Boros PW: Grading the severity of airways obstruction: new wine in new bottles. Eur Respir J 2014;43: 505-512.
17 Boeck L, Soriano JB, Brusse-Keizer M, Blasi F, Kostikas K, Boersma W, Milenkovic B, Louis R, Lacoma A, Djamin R, Aerts J, Torres A, Rohde G, Welte T, Martinez-Camblor P, Rakic J, Scherr A, Koller M, van der Palen J, Marin JM, Alfageme I, Almagro P, Casanova C, Esteban C, Soler-Cataluña JJ, de-Torres JP, Miravitlles M, Celli BR, Tamm M, Stolz D: Prognostic assessment in COPD without lung function: the B-AE-D indices. Eur Respir J 2016;47:1635-1644.

18 Lange P, Celli B, Agustí A, Boje Jensen G, Divo M, Faner R, Guerra S, Marott JL, Martinez FD, Martinez-Camblor P, Meek P, Owen CA, Petersen H, Pinto-Plata V, Schnohr P, Sood A, Soriano JB, Tesfaigzi Y, Vestbo J: Lung-function trajectories leading to chronic obstructive pulmonary disease. N Engl J Med 2015;373:111-122.

19 Soriano JB, Paton J, Martin Burrieza F, Bill W, Pannetier C, Aliberti S, Adcock IM, Wagers S, Migliori GB: The ERS Research Agency: the beginning. Eur Respir J 2016;47:1017-1023.

20 E-Learning Resources: Global Lung Function Initiative. http://www.ers-education.org/ guidelines/global-lung-function-initiative. aspx (accessed June 29, 2016). 